\title{
Article \\ Complex Processing of Saponite Waste from a Diamond-Mining Enterprise
}

\author{
Olga Zubkova ${ }^{1, *}$, Aleksey Alexeev ${ }^{1}$, Arseniy Polyanskiy ${ }^{1, *}$, Kirill Karapetyan ${ }^{1}$, Olga Kononchuk ${ }^{2}$ and \\ Markus Reinmöller ${ }^{2}$ \\ 1 Department of Mineral Raw Materials Processing, Saint Petersburg Mining University 21st Line of V. I., 2, \\ 199106 St. Petersburg, Russia; 4alexeev@mail.ru (A.A.); Karapetyan_KG@pers.spmi.ru (K.K.) \\ 2 TU Bergakademie Freiberg, Institute of Energy Process Engineering and Chemical Engineering, \\ Fuchsmuehlenweg 9D, 09599 Freiberg, Germany; olga.kononchuk@student.tu-freiberg.de (O.K.); \\ Markus.Reinmoeller@iec.tu-freiberg.de (M.R.) \\ * Correspondence: Zubkova-phd@mail.ru (O.Z.); Arseniy34@yandex.ru (A.P.)
}

check for updates

Citation: Zubkova, O.; Alexeev, A.; Polyanskiy, A.; Karapetyan, K.; Kononchuk, O.; Reinmöller, M. Complex Processing of Saponite Waste from a Diamond-Mining Enterprise. Appl. Sci. 2021, 11, 6615. https://doi.org/10.3390/app11146615

Academic Editor: Yosoon Choi

Received: 11 June 2021

Accepted: 15 July 2021

Published: 19 July 2021

Publisher's Note: MDPI stays neutral with regard to jurisdictional claims in published maps and institutional affiliations.

Copyright: (c) 2021 by the authors. Licensee MDPI, Basel, Switzerland. This article is an open access article distributed under the terms and conditions of the Creative Commons Attribution (CC BY) license (https:// creativecommons.org/licenses/by/ $4.0 /)$.

\begin{abstract}
The solution of the sludge utilization problem and yield increase at processing plants have great importance today all over the world. Disasters associated with the tailings dams failures have madeus develop technologies of tailings sludge utilization as a commercial product, reducing the environmental damage on the regions of mineral extraction. This research aimed to provide new data, methods and an analytical approach to solve the saponite sludge accumulation problem on mining enterprises with silicate coagulant to increase the rate of cycle water clarification for the enrichment process and the recycling of sludge to reduce its hazardous effect. Samples were taken in the deposit located in the north of the European part of Russia, where diamond bearing ore contain montmorillonite minerals, mostly saponite, which is considered to be a perspective secondary product. The content of this mineral in the sludge is above $20 \mathrm{wt} . \%$. Saponite is a clay mineral with the general chemical formula $(\mathrm{Ca}, \mathrm{Na})_{0.3}\left(\mathrm{Mg}, \mathrm{Fe}^{2+}\right)_{3}(\mathrm{Si}, \mathrm{Al})_{4} \mathrm{O}_{10}(\mathrm{OH})_{2} \cdot 4 \mathrm{H}_{2} \mathrm{O}$. The mineral has high adsorption, ion exchange, and catalytic and filtration properties; due to the developed diffuse layer, saponite particles are highly stable in an aqueous medium - the resulting suspension is highly stable and has slow sedimentation. During the research, a positive effect on the sedimentation process of clay saponite particles was established, due to the introduction of a coagulant containing $70 \%$ tricalcium silicate, at a dosage of $2 \mathrm{~g} / \mathrm{dm}^{3}$ coagulant; the degree of purification of water containing the saponite clay suspension is $99 \%$. The condensed sediment after the thermal drying and with the limestone addition can be used again as a coagulant or secondary product with enhanced properties; therefore, the sludge will be processed, and not stored.
\end{abstract}

Keywords: saponite; diamond-mining plant; circulating water; calcium aluminosilicate reagent; sedimentation; mineral phases; modeling

\section{Introduction}

Assessing the status of the environment and natural systems' well-being, protecting them effectively and appropriately is a major concern of society and the economy. The Lomonosov diamond deposit is the main locality of the diamond mining industry in Northern European Russia. Its development is accompanied by a violation of the lithological basis of the landscape, changes in the hydrological characteristics of the watercourses in the area of the deposit, and an impact on groundwater. In general, the main factors affecting the components of the environment are as follows [1]:

- Dust emissions from open mining that pollute the air and form highly significant anthropogenic anomalies.

- Deflation and erosion of containment facility tailing dumps, forming intensive scattering streams in water systems and relatively local technogenic pollution areas in soils. 
- Drainage from underground mining and quarries, which generates intensive, extended scattering streams in water systems.

- Effluents from processing plants after treatment facilities, polluting water systems.

It is very important to note that, due to the problems of environmental degradation, most countries around the world are developing technologies involving a completely different principle for handling resources and waste related to processing, including mining.

This is the $3 R$ principle [2,3]:

- Reduce: cutting waste generation.

- Reuse: employing waste materials.

- Recycle: processing the waste.

As increased attention has been paid to the scarcity of natural resources and the problem of waste pollution over the past few years, interest in investigating the effects of these issues and preventing the damage they cause have forced the further development of safe technologies for rational resource use [4]. The Russian enterprise has one of the main important unresolved environmental problems: it lacks a highly efficient closed water cycle. This reduces the efficiency of the process used to enrich the diamond-bearing ore.

At the Lomonosov deposit, saponite predominates in the composition of the kimberlites (more than $70 \mathrm{wt} \%$ ). The deposit is located in the central part of the White Sea Kuloi plateau on the bend of the Zolotitsa River, which flows into the White Sea. This deposit is shaped by six kimberlite pipes: "Pomorskaya", "Arkhangelskaya", "Karpinsky 1", "Karpinsky 2", "Pionerskaya" and "Lomonosov".

The ore dressing technology created by Russian specialists at enrichment plants corresponds to the global standard and exceeds that level in terms of individual technical characteristics. At the same time, the main flaw of enrichment in diamond mining in the Arkhangelsk diamond province (ADP) is the lack of understanding of the material costs required to eliminate the shortcomings of the existing method of enrichment and waste disposal at the processing plant. According to the material balance, in order to obtain $0.42 \mathrm{~g}$ of diamonds from the Arkhangelsk and Karpinsky-1 pipes, 4 tonnes of ore are processed; this drawback is the reason why the environmental aspects of this issue need to be studied thoroughly [5].

The mineralogical and crystal chemical characteristics of saponite create major technological obstacles to solving the problem of organizing a closed water scheme at the company's processing plant. Water is found in nature in three different states: gaseous, liquid, or solid.

The physicochemical water treatment system is the combination of substances or bodies used in the technology of processing diamond ores: these are in interaction with and separated from the external environment by real or imaginary boundaries. In this case, water is used as the main technological reactant, which is repeatedly used for water inside a circulating system [6]. The chemical and technological process of grinding the diamond-saponite ore is carried out in aqueous solutions.

The operating time of the processing plant is presented in Figure 1 for each month in 2017. The graph depicts four different climatic conditions-winter, spring, summer, and autumn - using the one-component water chart presented in Figure 1 and the temperature climate conditions corresponding to the Arkhangelsk region. The graph shows that from April to October, for the concentrator, the plant is in a liquid state and with a lower content of suspended substances, while from November to April, everything below the 0 line is the formation of ice on the tailings and the natural thickening of a liquid water-slurry into a pulp with a high content of suspended substances. 


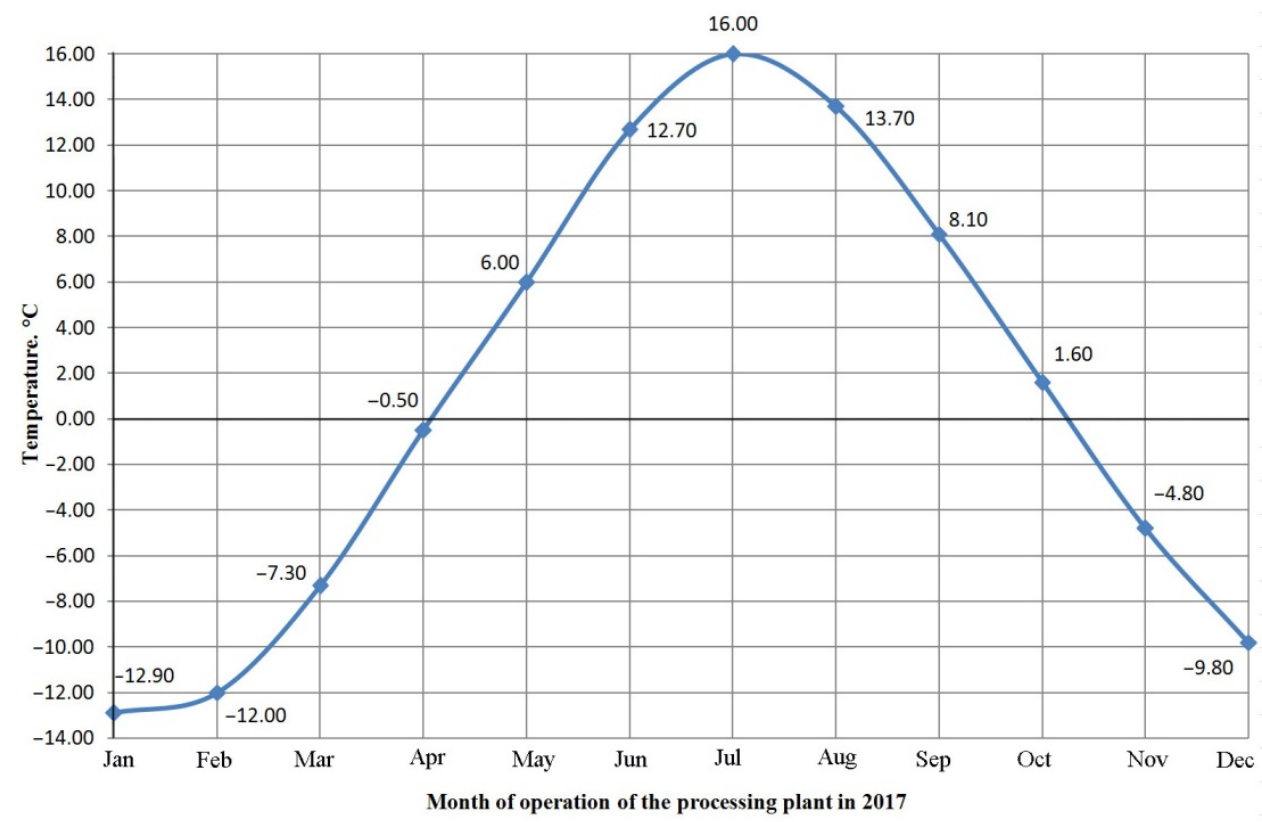

Figure 1. Influence of climatic parameters on the implementation of the technological process of the concentration plant $[7,8]$.

These shortcomings can lead to a decrease in the extraction of diamonds, using the technological processes of dense medium and X-ray luminescent concentrators, and to the need to find clean water for consumption and improve the environmental safety of the enterprise. Research is needed on the mineral and granulometric composition of the pulp after the enrichment of ore at the tailings and water after the tailings when the water enters the enrichment (circulating water).

The main distinguishing feature of the deposit from other diamond-bearing ores is the presence of saponite in the host rock. Large-scale saponite accumulation has a negative impact on the environment, especially the ecology. Uponcontact with water, this clay mineral swells (the value of the swelling index corresponds to $\mathrm{I}=5 \mathrm{~mL} / 2 \mathrm{~g}$ ) and all processed pulp entering the tailings pond has a gel-like consistency, which takes a long time to precipitate under natural conditions, thereby reducing the efficiency of diamond enrichment, leading to the premature filling of the tailings pond and to environmental degradation. The aim of the research is to study the mineral, chemical and granulometric compositions of ore and sludge, followed by the synthesis of an active inorganic mineral coagulant based on alkaline aluminosilicate raw materials, with further utilization of the condensed saponite sludge as a secondary product and way of regeneration of the used mineral coagulant.

\section{Literature Review}

In 2002, V.I. Vaganov, Yu.K. Golubev and V.E. Minorin created a methodological guide for assessing the forecast resources of diamonds and noble and non-ferrous metals [9]. This guide examines the methodological basis and techniques for identifying promising areas and estimating the diamond resources there. The paper classifies the main types of diamond deposits. In addition, quantitative geological and industrial models of diamond deposits are described, the characteristics of which can be used to calculate the material balance of industrial facilities [9]. According to their data, today, $97 \%$ of mined diamonds in Russia come from primary deposits and they account for the bulk of the balance reserves (94.7\%).

An increase in production at the Lomonosov diamond deposit entails a number of problems, one of which is the utilization of a large volume of clay rock tailings. One distinctive feature of this diamond deposit is the high content of dioctahedral and trioctahedral 
clay minerals of the smectite group found in the kimberlite rock. This is characteristic of the alkaline and ultrabasic rocks of the diamondiferous Arkhangelsk province. This phenomenon is called the "claying" of kimberlites [10]. Over the course of technological processes using water at the concentrator, waste is formed (sludges) with a large concentration of clay particles, predominantly saponite mineral. A significant increase in the tailing volume is associated with the increased content of suspended smectites in the water, causing the tailing dump size to increase, leading to its premature overflow. Those facts force the enterprise to build a dam and to occupy new areas. During the first two years of operation (from 2005 to 2007), an impoundment was built in the tailings pond. At the first stage, the dam was $116 \mathrm{~m}$ high. In December 2007, the second stage of the dam was put into operation. This was $120 \mathrm{~m}$ high, ensuring the operation of the tailing dump in 2011. The annual volume of ore processing in 2009 amounted to 1,050,000 tonnes. When calculating the volume of the stacked tailings, the density of the particles is assumed to be $2.7 \mathrm{~g} / \mathrm{cm}^{3}$. In parallel to the development of the field, the volume of tailings to be stored increases, and the capacity required to fill the tailing pond grows accordingly. It seems natural that with such volumes of tailings, it is necessary to search for ways to use their most interesting component: smectite-containing rock [10].

According to the material balance, the main drawback of the saponite ore dressing method currently used in the Arkhangelsk region is that almost the entire volume of crushed ore must be passed through the tailing pond separation system when processing large volumes of a rock mass. The further development of deposits will lead to a significant increase in the volume of pulp (water and saponite) in sludge reservoirs. Due to the highly dispersed particles and the large diffuse layer, the saponite particles are highly resistant to precipitation in water. Moreover, the presence of micro-aggregates of clay minerals along with sand grains, which determine the physical and mechanical properties of formed structures, negatively affects the stability of tailing dams [10].

The disadvantages of thickening the saponite-containing suspension using highcompression thickeners are high capital costs, high consumption of reagents, high power consumption, and several other shortcomings. The use of domestic and foreign coagulants and flocculants to precipitate suspensions because of their high ion exchange capacity has not yet yielded an effective result, and information has been revealed about the restabilization of the suspension after the addition of coagulants.

A. I. Alekseev is working on the processing of aluminosilicate raw materials, ion exchange in a clay suspension, and the complex processing of apatite-nepheline ores on the basis of creating closed technological schemes [11]. P. V. Utin investigated the effect of carbon dioxide and aluminum sulfate on the deposition of saponite clay [12]. M. A. Pashkevich developed a method for sludge processing; this is a method for increasing tailing dumps [13]. A. S. Tutygin studied the influence of the nature of the electrolyte in the coagulation process of saponite-containing clay minerals [14]. V. M. Sizyakov engaged in the synthesis of a reagent (calcium hydrocarboaluminates) based on $\mathrm{CaCO}_{3}$ in an aluminatealkaline system with its further application as a coagulant $[15,16]$. S. A. Bakharev applied the gravitational-acoustic method to coagulate saponite particles in circulating water [17].

However, the works of the above authors do not touch upon the calculation of saponite's effective rate of deposition and its compaction in the sludge accumulator of the diamond mining concentrator. In order to achieve the goals that have been set, new complex technology must be developed and implemented that can be used throughout the processing of saponite-bearing diamond waste, and customers must be encouraged to purchase building materials and other products made from raw materials, especially those resulting from waste (recycling) or the reclamation of disturbed lands in quarries.

\section{Material Balance Calculation}

According to the company report for 2017 [7], 2,640,000 carats of diamonds were produced. The amount of ore processed at the processing plant in the same year is $3,259,000$ tonnes. 
To calculate the ratio, it is necessary to convert the data obtained into kilograms. We calculate the mass of all extracted diamonds based on a ratio of 1 carat $=0.0002 \mathrm{~kg}$ :

Weight of all diamonds $\left(m_{\text {Diamonds }}\right)=2,640,000$ carats $\times 0.0002 \mathrm{~kg} /$ carat $=528 \mathrm{~kg}$.

We also convert the mass of ore processed from the material $\left(10^{6} \mathrm{~kg}\right.$ of ore using material from the mine) at the processing plant:

$$
\text { Ore mass }\left(m_{\text {Ore }}\right)=3,259,000 \mathrm{t}=3259 \times 10^{6} \mathrm{~kg}
$$

Calculating the ratio of the mass of all the diamonds obtained to the mass of the processed ore, we find that the mass of all diamonds achieved from the ore mass equals the following:

$$
528 \mathrm{~kg} /\left(3259 \times 10^{6} \mathrm{~kg}\right) \approx 1.62 \times 10^{-7}
$$
monds.

Thus, $1 \mathrm{~kg}$ of ore delivered to the processing plant contains $1.62 \times 10^{-7} \mathrm{~kg}$ of dia-

The approximate ratio of the mass of jewelry-quality diamonds to the mass of processed ore is also a point of interest. Gem-quality diamonds make up $10 \%$ of the total amount of diamonds extracted at the processing plant [7]. Thus, one can calculate this ratio by taking $10 \%$ of the previous number:

Weight of gem-quality diamonds per ore mass $\left(\mathrm{m}_{\text {Gem-quality }}\right)=1.62 \times 10^{-7} \times 0.1=1.62 \times 10^{-8} \mathrm{~kg}$

We find that $1 \mathrm{~kg}$ of ore received at the processing plant contains $1.62 \times 10^{-8} \mathrm{~kg}$ of diamonds of jewelry quality.

The value of $528 \mathrm{~kg}$ of diamonds is negligible in comparison with $3259 \times 10^{6} \mathrm{~kg}$ of extracted ore. Thus, after the processing process, the tailings dump receives almost the same mass of waste as the mass of ore delivered to the processing plant: on average, it is about 3250 million tonnes of waste per year.

\section{Investigation Methods}

The concentration of suspended particles was investigated by turbidity measurements and concentration calculations with respect to formazine suspension standards, using spectrophotometer UNICO 2802S.

The density measurements of clay suspensions samples were carried by hydrometer relative density measurements with respect to water.

X-ray diffractometric analysis (XRD) of powder mineral samples was carried out on the Shimadzu XRD-7000 diffractometer, and the plotted graphs were analyzed using open access databases.

Granulometric analysis of samples was carried out on Horiba LA950 laser diffraction particle size analyzer.

The chemical composition of the samples was investigated, using X-ray fluorescence analysis on Shimadzu XRF-1800 with the characteristic line of chemical elements spectrum and $0.001 \mathrm{wt} \%$ limitation.

The equilibrium of obtaining calcium aluminosilicate from raw material and from the condensed suspension was calculated, using the FactSage ${ }^{\mathrm{TM}}$ program.

The kinetics of the suspension sedimentation rate was registered manually during 35 min settlement of suspension with a concentration of suspended particles equal to $3500 \mathrm{mg} / \mathrm{dm}^{3}$.

Samples of processed and unprocessed suspension were investigated on a TESCAN Vega electron scanning microscope with a field emission cathode at an accelerating voltage of $20 \mathrm{kV}$ in secondary electron detection mode to investigate flocula forming by the developed mineral coagulant. 


\section{Research on the Mineral Composition of Pulp after Enrichment}

The clay mineral saponite forms a finely dispersed clay suspension with a concentration of saponite in the circulating water of $5-200 \mathrm{~g} / \mathrm{dm}^{3}$ and colloidal particles, which are 1-3 $\mu \mathrm{m}$ in size. Without treatment with coagulants and flocculants, the deposition of the clay mineral saponite ends after 1.5 years.

Because of the properties of the saponite mineral, which has the characteristic not only to "swell", but also to disperse and stabilize, forming a non-precipitating fine-grained gel-like structure bonded with $\mathrm{Ca}$ and $\mathrm{Mg}$ ions $(\sim 20 \%)$, the tailing sites allocated by its project increase $[18,19]$.

The pure mineral saponite-stevensite has the mineralogical structural formula $\mathrm{Na}_{\mathrm{x}} \mathrm{Mg}_{3}$ $\left(\mathrm{Al}_{\mathrm{x}} \mathrm{Si}_{4-\mathrm{x}} \mathrm{O}_{10}\right)\left(\mathrm{OH}_{2}\right) \cdot 4 \mathrm{H}_{2} \mathrm{O}$, a monoclinic syngony, a density of $2 \mathrm{~g} / \mathrm{cm}^{3}$, and a Mohs hardness of two (refined data: density $2.3-2.5 \mathrm{~g} / \mathrm{cm}^{3}$, Mohs hardness 2.5) [20].

The chemical and physical characteristics of the liquid phase samples were investigated and found to be almost identical and characterized by slightly base $\mathrm{pH}$ values, low oxidation-reduction potential, and a small amount of mineralization.

According to the information provided by the company, it is not difficult to obtain the required quality discharge $(500 \mathrm{mg} / \mathrm{L})$, but it is impossible to obtain a thickened product with a density of $70 \mathrm{wt} \%$. The increased content of clay particles in the circulating water to enrich the ore means that the scheme has to be scaled up or additional water must be gathered from other circulating water for primary sources.

The soil composition is heterogeneous and varies in the depth of occurrence. Thus, in the upper layers, its composition is a mixture of sandy loam (up to $30 \mathrm{wt} \%$ ), saponite (up to $60 \mathrm{wt} \%$ ), and vermiculite (up to $10 \mathrm{wt} \%$ ). When the soil depth increases, the content of saponite increases (up to $90 \mathrm{wt} \%$ ) and, accordingly, the content of sandy loam decreases (down to $5 \mathrm{wt} \%$ ), as does that of vermiculite (down to $5 \mathrm{wt} \%$ ). The mineral composition is shown in Figure 2 and Table 1.

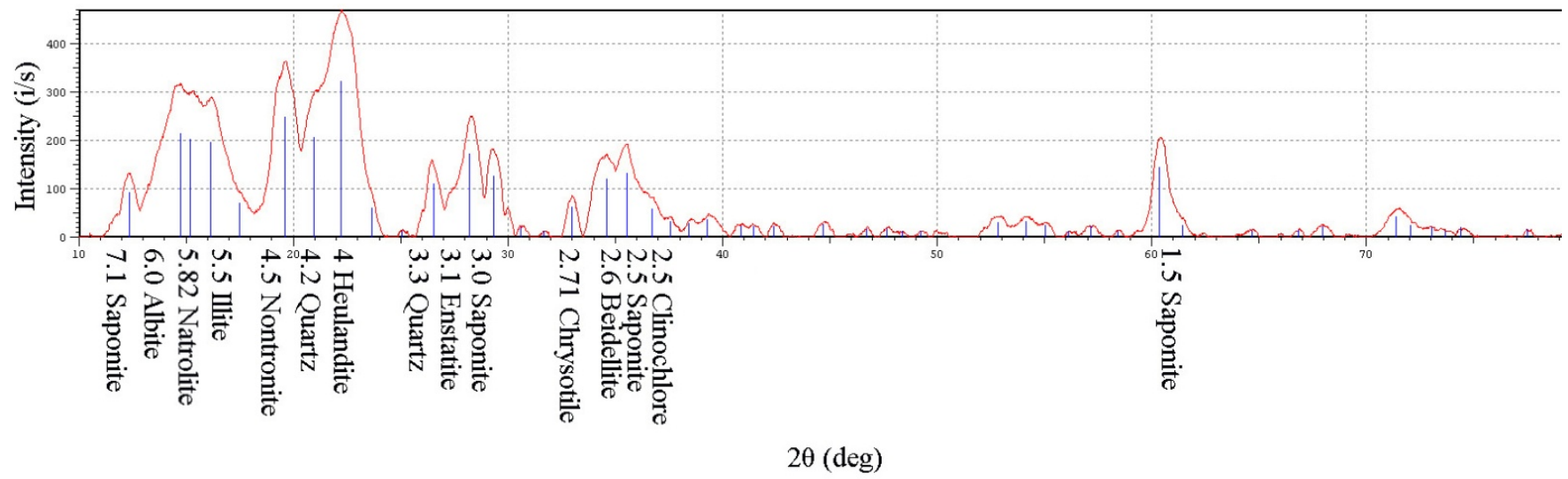

Figure 2. The ore mineral composition. 
Table 1. Mineral composition of saponite diamond-bearing ore from the Arkhangelsk pipe.

\begin{tabular}{|c|c|c|c|c|c|c|c|}
\hline Mineral & $2 \theta, \circ *$ & $\mathrm{~d}, \AA$ А* & $\mathrm{I} / \mathrm{I} 0, \% * * *$ & Structural Formula & $\begin{array}{l}\text { Density, } \\
\mathrm{kg} / \mathrm{m}^{3}\end{array}$ & $\begin{array}{c}\text { Mohs } \\
\text { Hardness }\end{array}$ & $\begin{array}{l}\text { Content, } \\
\text { wt } \%\end{array}$ \\
\hline Enstatite & 28.22 & 31.6 & 53 & $\mathrm{Mg}_{2}\left[\mathrm{Si}_{2} \mathrm{O}_{6}\right]$ & 3300 & 5.5 & 6.5 \\
\hline Phlogopite & 17.48 & 50.7 & 21 & $\mathrm{KMg}_{3} \mathrm{AlSi}_{3} \mathrm{O}_{10}(\mathrm{OH})_{2}$ & 2780 & 2.5 & 4.9 \\
\hline \multirow{2}{*}{ Quartz } & 20.98 & 42.3 & 64 & \multirow{2}{*}{$\alpha-\mathrm{SiO}_{2}$} & \multirow{2}{*}{2650} & \multirow{2}{*}{7.0} & \multirow{2}{*}{12.1} \\
\hline & 26.53 & 33.6 & 34 & & & & \\
\hline Clinochlore & 36.70 & 24.4 & 18 & $\mathrm{Mg}_{5} \mathrm{Al}\left(\mathrm{AlSi}_{3} \mathrm{O}_{10}\right)(\mathrm{OH})_{8}$ & 2628 & 2.5 & 2.1 \\
\hline Albite & 14.60 & 60.0 & 67 & $\mathrm{Na}\left[\mathrm{AlSi}_{3} \mathrm{O}_{8}\right]$ & 2615 & $6.0-6.5$ & 8.3 \\
\hline Chrysotile & 32.96 & 27.1 & 19 & $\mathrm{Mg}_{3} \mathrm{Si}_{2} \mathrm{O}_{5}(\mathrm{OH})_{4}$ & 2550 & 3.0 & 2.4 \\
\hline \multirow{2}{*}{ Illite } & 16.16 & 54.8 & 61 & \multirow{2}{*}{$\begin{array}{c}\mathrm{K}_{0.5-1.5}(\mathrm{Al}, \mathrm{Mg}, \mathrm{Fe})_{2-3} \cdot\left(\mathrm{Si}_{4^{-}}\right. \\
\left.{ }_{x} \mathrm{Al}_{\mathrm{x}} \mathrm{O}_{10}\right) \cdot(\mathrm{OH})_{2.5} \cdot \mathrm{nH}_{2} \mathrm{O}\end{array}$} & \multirow{2}{*}{2550} & \multirow{2}{*}{2.0} & \multirow{2}{*}{9.2} \\
\hline & 23.68 & 37.5 & 19 & & & & \\
\hline \multirow{5}{*}{ Saponite } & 12.37 & 71.5 & 29 & \multirow{5}{*}{$\begin{array}{c}\left(\mathrm{Ca}_{0.5, \mathrm{Na}}\right)_{0.3}\left[\mathrm{Mg},\left(\mathrm{Fe}^{2+}\right)\right]_{3} \\
\quad(\mathrm{Si}, \mathrm{Al})_{4} \mathrm{O}_{10}(\mathrm{OH})_{2}\end{array}$} & \multirow{5}{*}{2500} & \multirow{5}{*}{2.5} & \multirow{5}{*}{20.3} \\
\hline & 29.32 & 30.4 & 39 & & & & \\
\hline & 35.54 & 25.2 & 37 & & & & \\
\hline & 60.36 & 15.3 & 45 & & & & \\
\hline & 71.38 & 13.2 & 13 & & & & \\
\hline Nontronite & 19.62 & 45.2 & 77 & $\begin{array}{c}\mathrm{Na}_{0 \cdot 3} \mathrm{Fe}_{2}\left((\mathrm{Si}, \mathrm{Al})_{4} \mathrm{O}_{10}\right) \\
(\mathrm{OH})_{2} \cdot \mathrm{nH}_{2} \mathrm{O}\end{array}$ & 2300 & 2.0 & 9.4 \\
\hline Natrolite & 15.20 & 58.2 & 63 & $\mathrm{Na}_{2}\left[\mathrm{Al}_{2} \mathrm{Si}_{3} \mathrm{O}_{10}\right] \cdot 2 \mathrm{H}_{2} \mathrm{O}$ & 2260 & $5.0-5.5$ & 7.9 \\
\hline Heulandite & 22.24 & 39.9 & 100 & $\left(\mathrm{Me}_{0.5-1}\right)_{9}\left[\mathrm{Al}_{9} \mathrm{Si}_{27} \mathrm{O}_{72}\right] \cdot 24 \mathrm{H}_{2} \mathrm{O}$ & 2170 & 4.0 & 12.3 \\
\hline Beidellite & 34.58 & 25.9 & 37 & $\begin{array}{c}(\mathrm{Na}, \mathrm{Ca})_{0 \cdot 3} \mathrm{Al}_{2}(\mathrm{Si}, \mathrm{Al})_{4} \\
\mathrm{O}_{10}(\mathrm{OH})_{2} \mathrm{nH}_{2} \mathrm{O}\end{array}$ & 2150 & 1.0 & 4.6 \\
\hline \multicolumn{7}{|c|}{ Total } & 100 \\
\hline
\end{tabular}

${ }^{*} 2 \theta$ —scattering angle, ${ }^{* *} \mathrm{~d}$-interplanar distance, ${ }^{* * *} \mathrm{I} / \mathrm{I}_{0}$-intensity ratio.

The results of the X-ray diffractometric analysis (XRD) are summarized in Table 1. According to the data obtained, almost $55.4 \mathrm{wt} \%$ of the suspension is represented by complex silicates and $34 \mathrm{wt} \%$ by aluminosilicates of a layered structure belonging to various mineralogical groups: montmorillonite (nontronite, saponite, beidellite) and zeolites (natrolite) [21].

All of these minerals can be attributed to the light fraction of the matter suspended in the recycled water of the regional processing plant. This is freely suspended throughout the volume. The minerals' precipitation is difficult not only due to the relatively low density of minerals but also due to their lamellar structure and ability to interact with water. This ability is most predominant in saponite and other minerals of the montmorillonite group due to the weak intermolecular bonds between three-layer packages containing two silicon-oxygen tetrahedral layers and an octahedral layer, with aluminum cations located between them. Due to these structural features, water and other polar liquids can freely infiltrate between the layers, increasing the interplane distance from $0.92 \mathrm{~nm}$ to $14 \mathrm{~nm}$, which causes a significant change in the density of the mineral and leads to the formation of a non-settling gel mass. Taking into account the sufficient mineral deposition rate of particles of enstatite, phlogopite, albite, and quartz, the remainder is represented by clay minerals, of which about $35 \%$ are in the montmorillonite group.

In order to determine how the montmorillonite group influencing the diamond enrichment process is subsequently disposed, studies were conducted on the mineral composition of suspended particles in recycled water entering the processing and storage in the tailing basin. According to the obtained data, the following minerals are in the suspended state: 
saponite $24 \mathrm{wt} \%$, beidellite $14.6 \mathrm{wt} \%$, and nontronite $19.2 \mathrm{wt} \%$. These make up the bulk of the pulp stored in a watered state in the tailing basin.

The chemical composition of the sample shows that quartz-containing, iron-containing, and magnesium-containing substances, which are distributed over the entire surface of the tailing pond, mainly enter the environment.

\section{Granulometry Investigation of Saponite Suspension}

According to the technological scheme, the recycled water supply system consists of a concentrating plant, tailing dump, and concentrating mill. Water is reserved after the tailings and fed first to the grinding mill, then to the classifiers. To study the granulometric composition of suspensions, a Horiba LA-950 express universal laser particle size distribution analyzer was used to determine the granulometric composition of the discharge from the classifiers after the saponite ore dressing process (Figure 3).
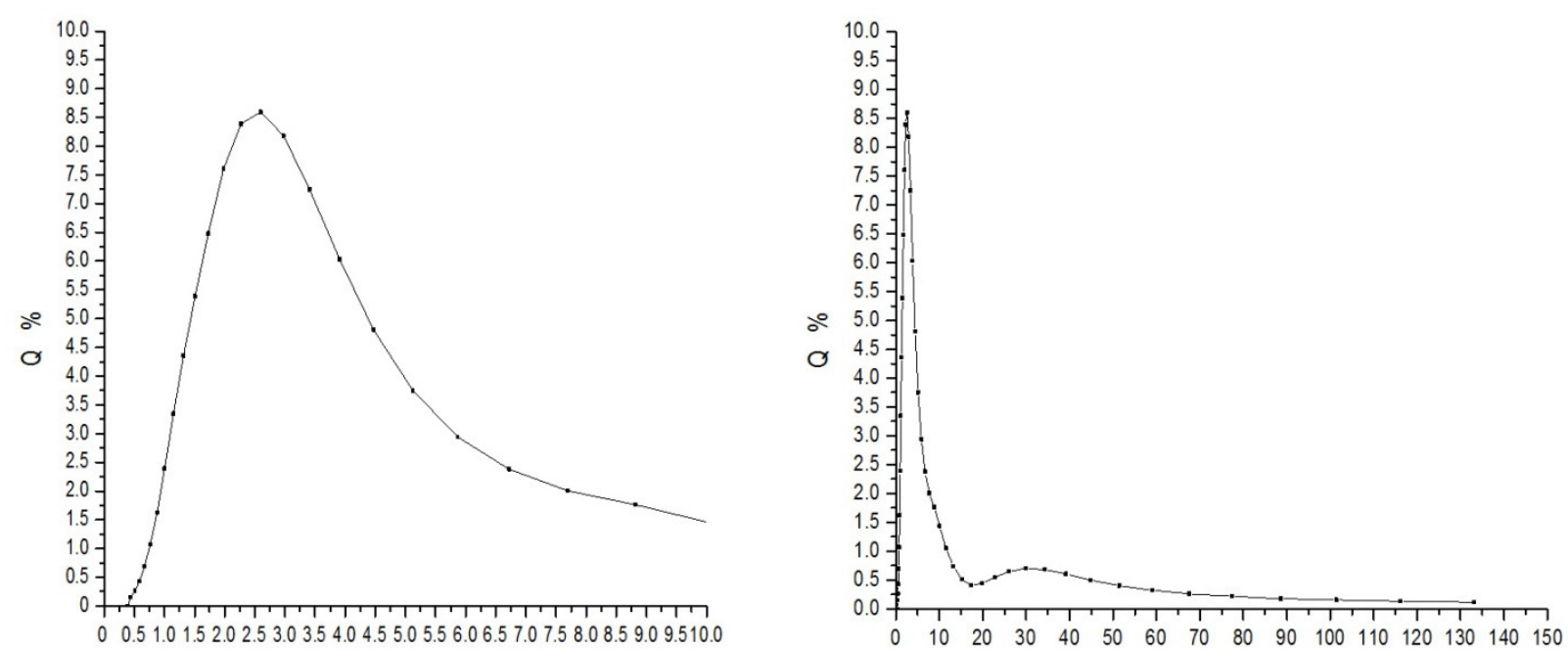

Figure 3. Granulometric composition of the discharge from the classifier.

According to the granulometry results, the average particle size of saponite sludge is $2.6 \mu \mathrm{m}$. In this case, the deposition rate decreases significantly, and the water flow turbulence dominates the particle movement. Saponite ore particles are highly dispersed and hardly precipitate at all, due to the chaotic motion of part of the water.

The deposition rate for given particle size is calculated using Equation (1):

$$
w_{\mathrm{oc}}=\frac{d^{2}\left(\rho-\rho_{\mathrm{c}}\right) g}{18 \mu_{\mathrm{c}}}
$$

The deposition rate for the particle size is calculated and equals $5.7 \times 10^{-8} \mathrm{~m} / \mathrm{s}$, suggesting that the saponite pulp is close to a colloidal solution with its sedimentation rate and the particles do not settle under the action of gravity in a reasonable amount of time. In laboratory conditions, saponite precipitation without the application of coagulants and flocculants is about $49 \mathrm{~mm}$ per day.

\section{Synthesis of Inorganic Precipitant}

For effective deposition, a calcium aluminosilicate (CAS) reagent was developed with the St. Petersburg Mining University. The calcium aluminosilicate reagent is synthesized in the temperature ranges of the crystallization of tricalcium silicate and tricalciumaluminate [22]. Thus, a method is proposed for obtaining an active coagulant in the wastewater treatment process through the decomposition of the initial silicate reagent. The properties of the coagulant obtained are associated with the structural features of the included 
crystalline compounds. The synthesis of calcium silicates depends on the initial ratio of $\mathrm{CaO}: \mathrm{SiO}_{2}$ in the recommended ratio and the following temperature range:

$$
\begin{gathered}
\mathrm{xCaO}+\mathrm{ySiO}_{2} \stackrel{773-1372 \mathrm{~K}}{\rightarrow} 2 \mathrm{CaO} \cdot \mathrm{SiO}_{2} \stackrel{1273-1473 \mathrm{~K}}{\rightarrow} \\
3 \mathrm{CaO} \cdot 2 \mathrm{SiO}_{2} \stackrel{1373-1573 \mathrm{~K}}{\rightarrow} \mathrm{CaO} \cdot \mathrm{SiO}_{2} \stackrel{1373-1573 \mathrm{~K}}{\rightarrow} 2 \mathrm{CaO} \cdot \mathrm{SiO}_{2}
\end{gathered}
$$

Thermochemical equilibrium calculations of the simple system $\mathrm{CaO}: \mathrm{SiO}_{2}$ as a function of temperature with consideration of extra $\mathrm{CaO}$ - and $\mathrm{SiO}_{2}$-bearing phases are visualized in Figure 4a. Here, the main mineral has the composition of $\mathrm{CaSiO}_{3}$ in different lattice geometries. In addition, a constant amount of $\mathrm{Ca}_{3} \mathrm{Si}_{2} \mathrm{O}_{7}$ is present. The calculations of the real system of sludge with the chemical composition from Table 2 resulted in slightly different chemical compositions, shown in Figure $4 \mathrm{~b} . \mathrm{CaO}$ and $\mathrm{SiO}_{2}$ are incorporated in various mineral phases-including solid solutions of different cations-dominated by calcium-magnesium silicates, which are transformed into other phases at increased temperatures. This calculation was performed under the condition that every atom can react with every other atom (no transport limitations, interfaces, kinetics, etc.).

$$
\mathrm{CaO}: \mathrm{SiO}_{2}=1: 1
$$

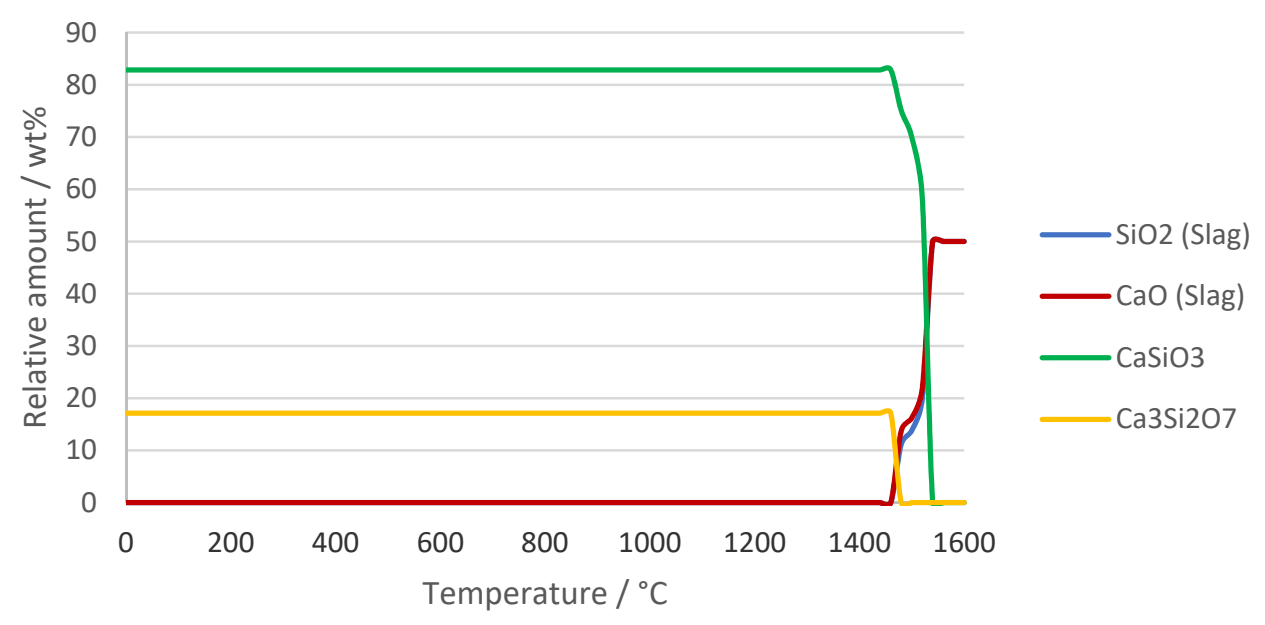

a)

\section{Sludge composition}

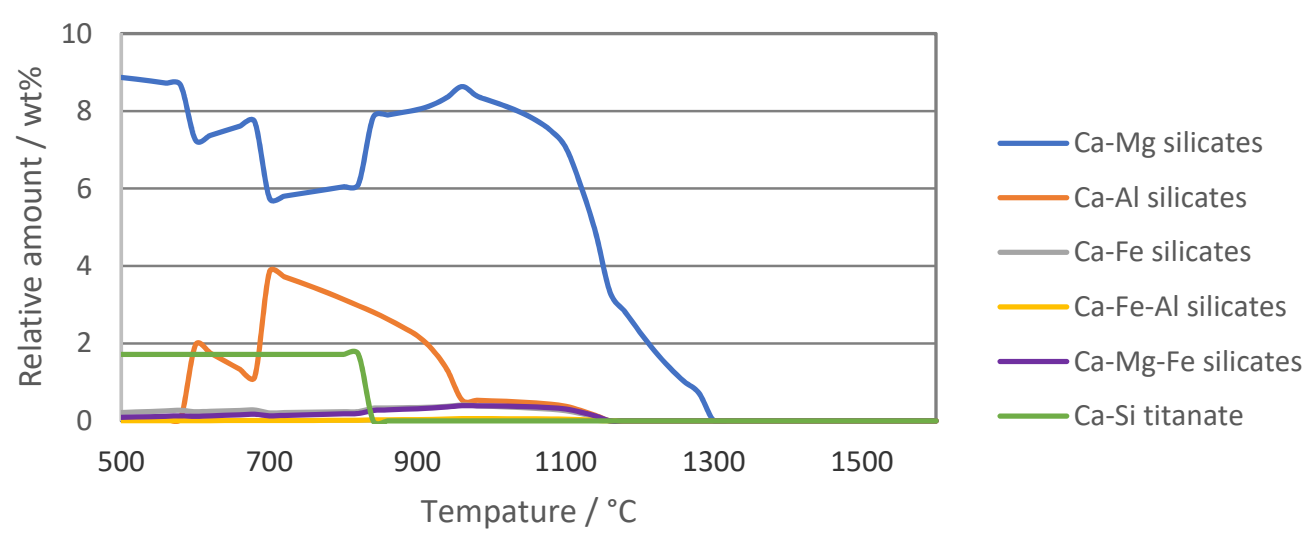

b)

Figure 4. FactSage ${ }^{\mathrm{TM}}$ equilibrium calculations of $\mathrm{CaO}-\mathrm{SiO}_{2}$ mineral phases: (a) calculation of equal composition of $\mathrm{CaO}: \mathrm{SiO}$, (b) calculation using the sludge composition (Table 2). 
Table 2. Oxide composition of sludge.

\begin{tabular}{ccc}
\hline No. & Oxide & Content, wt $\%$ \\
\hline 1 & $\mathrm{SiO}_{2}$ & 52.7 \\
\hline 2 & $\mathrm{Al}_{2} \mathrm{O}_{3}$ & 5.74 \\
\hline 3 & $\mathrm{MgO}$ & 24.1 \\
\hline 4 & $\mathrm{Fe}_{2} \mathrm{O}_{3}$ & 9.38 \\
\hline 5 & $\mathrm{CaO}$ & 2.9 \\
\hline 6 & $\mathrm{~K}_{2} \mathrm{O}$ & 1.6 \\
\hline 7 & $\mathrm{TiO}_{2}$ & 0.7 \\
\hline 8 & $\mathrm{MnO}$ & 0.15 \\
\hline 9 & $\mathrm{Na}_{2} \mathrm{O}$ & 1.1 \\
\hline 10 & Other & 1.63 \\
\hline
\end{tabular}

This composition of the obtained calcium aluminum silicate inorganic coagulant is determined by the ratio in the raw mix, which may vary in a narrow range, including four main minerals: tricalcium silicate, dicalcium silicate, tricalciumaluminate, and quaternary aluminoferrite [11]. The coagulant is a granulated mixture of self-separating slag and may be obtained from a number of clays and hydromica, containing calcium and magnesium silicates including hydroaluminosilicates with thermal treatment at about $1200-1300^{\circ} \mathrm{C}$. The reagent obtained was tested with an XRD-7000 X-ray diffractometer and the findings are presented in Figure 5. According to the data obtained during the X-ray diffraction analysis of the obtained sample, and according to I. A. Makarova [23], the primary coagulant is partly tricalcium silicate $3 \mathrm{CaO} \cdot \mathrm{SiO}_{2}$; the composition is presented in more detail in Table 3 .

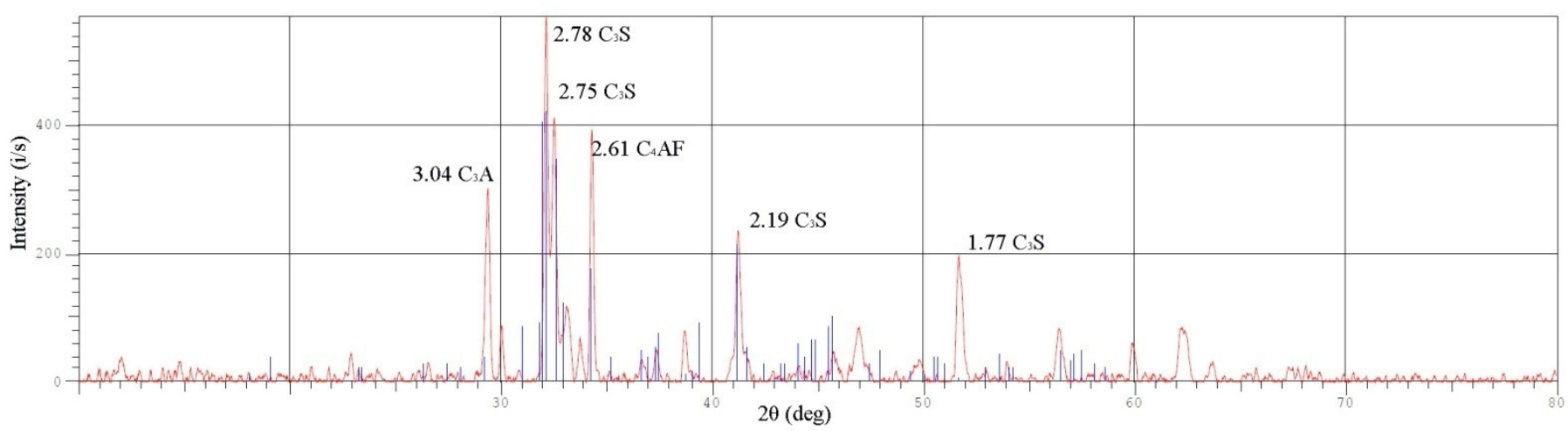

Figure 5. X-ray diffraction pattern of the minerals of the obtained coagulant.

Table 3. Mineral composition of the calcium-aluminum-silicate reagent.

\begin{tabular}{|c|c|c|c|c|c|}
\hline Mineral & $2 \theta, \circ *$ & $\mathrm{~d}, \mathrm{~nm} * *$ & $\mathrm{I} / \mathrm{I}_{0}, \% * * *$ & Structural Formula & Content, wt $\%$ \\
\hline \multirow{4}{*}{ Tricalcium silicate } & 32.14 & 2.78 & 100 & \multirow{4}{*}{ C3S } & \multirow{4}{*}{66.9} \\
\hline & 32.50 & 2.75 & 72 & & \\
\hline & 39.36 & 3.04 & 53 & & \\
\hline & 51.67 & 1.77 & 43 & & \\
\hline Tricalciumaluminate & 29.36 & 3.04 & 53 & $\mathrm{C} 3 \mathrm{~A}$ & 14.15 \\
\hline Tetracalciumaluminoferrite & 34.29 & 2.61 & 71 & C4AF & 18.9 \\
\hline Other & & various & & various & 0.05 \\
\hline
\end{tabular}

${ }^{*} 2 \theta$ — scattering angle, ${ }^{* *} \mathrm{~d}$-interplanar distance, ${ }^{* * *} \mathrm{I} / \mathrm{I} 0$-intensity ratio. 
The calcium-aluminum-silicate reagent is a mixture of several artificially obtained silicate minerals. The hydrolysis and hydration are described by the following Reactions (2)-(4) [8,24]:

For the main substance $C_{3} S$ :

$$
2\left(3 \mathrm{CaO} \cdot \mathrm{SiO}_{2}\right)+6 \mathrm{H}_{2} \mathrm{O} \rightarrow 3 \mathrm{CaO} \cdot 2 \mathrm{SiO}_{2} \cdot 3 \mathrm{H}_{2} \mathrm{O}+3 \mathrm{Ca}(\mathrm{OH})_{2}
$$

The initial hydrolysis of $\mathrm{C}_{3} \mathrm{~S}$ can proceed according to the reactions described below:

$$
\begin{gathered}
\mathrm{C}_{3} \mathrm{~S}\left(\mathrm{C} ; \mathrm{C}_{2} \mathrm{~S}\right) \stackrel{\mathrm{H}}{\rightarrow} \mathrm{C}_{2} \mathrm{~S}+\mathrm{Ca}^{2+}+2 \mathrm{OH}^{-} \\
\mathrm{C}_{2} \mathrm{~S} \stackrel{\mathrm{H}}{\rightarrow} 2 \mathrm{Ca}^{2+}+\mathrm{H}_{2} \mathrm{SiO}_{4}^{2-}+2 \mathrm{OH}^{-} \\
2 \mathrm{H}_{2} \mathrm{SiO}_{4}^{2-}+2 \mathrm{OH}^{-} \rightarrow \mathrm{Si}_{2} \mathrm{O}_{7}^{6-}+2 \mathrm{H}_{2} \mathrm{O}
\end{gathered}
$$

A related component is calcium orthosilicate. The structure of calcium orthosilicate $\left(\mathrm{Ca}_{2} \mathrm{SiO}_{4}\right)$ contains two calcium ions, so when it initially connects to the water, it undergoes hydrolysis:

$$
\mathrm{Ca}_{2} \mathrm{SiO}_{4}+2 \mathrm{H}_{2} \mathrm{O}=2 \mathrm{Ca}_{a q}^{2+}+\mathrm{H}_{2} \mathrm{SiO}_{4, a q}^{2-}+2 \mathrm{OH}_{a q}^{-}
$$

When calcium silicates come into contact with water, the chemical interaction with the formation of ions in the solution becomes primarily chemically driven: pure water is pushed to the surface from the interlayer space of the clay mineral saponite. Calcium hydrosilicate contains hydroxyl groups, which are shown to have cationic and anionic ion-exchange properties. The reaction when the $\mathrm{OH}$ group is replaced with cations in an alkaline medium consists of successive stages [8]:

- Adsorption: $\mathrm{Si}-\mathrm{OH}+\mathrm{Me}(\mathrm{OH})^{(\mathrm{x}-1)+}=\mathrm{Si}-\mathrm{OH} \mid \mathrm{HOMe}^{(\mathrm{x}-1)+}$;

- Condensation: $\mathrm{Si}-\mathrm{O}-\mathrm{Ca}^{2+}+\mathrm{An}^{2-}=\mathrm{Si}-\mathrm{O}-\mathrm{CaAn}$.

Reactions that occur at the end of the induction period are the following:

$$
\begin{gathered}
\mathrm{Ca}^{2+}+2 \mathrm{OH}^{-} \rightarrow \mathrm{Ca}(\mathrm{OH})_{2} \\
2 \mathrm{SiO}_{4}^{4-} \stackrel{\mathrm{H}}{\rightarrow} \mathrm{Si}_{2} \mathrm{O}_{7}^{6-}+2 \mathrm{OH}^{-} \rightarrow\left[\mathrm{SiO}_{3}\right]_{n}^{2-}+2 \mathrm{nOH}^{-}
\end{gathered}
$$

An ongoing increase in $\mathrm{OH}$ can be the result of silicate particle polymerization, which is formed during the resumed chemical activity of $C_{3} S$ at the end of the induction period [8].

The initial hydrolysis is considered to be primarily due to the leaching of excess calcium oxide from the $\mathrm{C}_{3} \mathrm{~S}$ structure (3). The end of the chemical induction period can be determined both by the crystallization of $\mathrm{CH}\left(\mathrm{Ca}(\mathrm{OH})_{2}\right.$, see $(7)$, and by the formation of a needle-like $\mathrm{C}-\mathrm{S}-\mathrm{H}$ gel (calcium hydrosilicate) from $\mathrm{C}_{2} \mathrm{~S}$. The main reaction that occurs during the growth of the needle $\mathrm{C}-\mathrm{S}-\mathrm{H}$ can be the polymerization of monosilicate ions in $\mathrm{C}_{3} \mathrm{~S}$ for the purpose of desilylation (8). The crystallization of the two products is clearly interdependent. It is possible that the growth of $\mathrm{CH}$ removes calcium not only from the solution, but also from $\mathrm{C}_{2} \mathrm{~S}$, thereby contributing to the polymerization of silica.

The second most important substance in the reagent is $\mathrm{C}_{4} \mathrm{AF}$. When added to an aqueous medium, the reaction proceeds, and calcium hydroferrite is formed [8]:

$$
4 \mathrm{CaO} \cdot \mathrm{Al}_{2} \mathrm{O}_{3} \cdot \mathrm{Fe}_{2} \mathrm{O}_{3}+\mathrm{mH}_{2} \mathrm{O}=3 \mathrm{CaO} \cdot \mathrm{Al}_{2} \mathrm{O}_{3} \cdot 6 \mathrm{H}_{2} \mathrm{O}+\mathrm{CaO} \cdot \mathrm{Fe}_{2} \mathrm{O}_{3} \cdot \mathrm{nH}_{2} \mathrm{O}
$$

The hydrolysis of $\mathrm{C}_{4} \mathrm{AF}$ can be described by the following equation:

$$
\mathrm{C}_{4} \mathrm{AF}+10 \mathrm{H} \rightarrow \mathrm{C}_{3} \mathrm{AH} 6+\mathrm{FH}_{3}+\mathrm{CH},
$$

where FH3 denotes a hydrated amorphous Fe-containing gel. 
For the third substance, $\mathrm{C}_{3} \mathrm{~A}$, which is a reagent, the interaction in an aqueous medium can be described by the equation with the formation of calcium aluminate hydrates [8]:

$$
3 \mathrm{CaO} \cdot \mathrm{Al}_{2} \mathrm{O}_{3}+6 \mathrm{H}_{2} \mathrm{O} \rightarrow 3 \mathrm{CaO} \cdot \mathrm{Al}_{2} \mathrm{O}_{3} \cdot 6 \mathrm{H}_{2} \mathrm{O}
$$

When $\mathrm{C}_{3} \mathrm{~A}$ is dissolved in water, it results in ions in solution according to the following equation:

$$
\mathrm{Ca}_{3} \mathrm{Al}_{2} \mathrm{O}_{6}+\mathrm{H}_{2} \mathrm{O} \rightarrow 3 \mathrm{Ca}^{2+}+2 \mathrm{Al}^{3+}+12 \mathrm{OH}^{-}
$$

When hydroxyl-AFm precipitates, the equation takes the following form:

$$
4 \mathrm{Ca}^{2+}+2 \mathrm{Al}^{3+}+12 \mathrm{OH}^{-}+7 \mathrm{H}_{2} \mathrm{O}=\mathrm{Ca}_{4} \mathrm{Al}_{2}(\mathrm{OH})_{12}+7 \mathrm{H}_{2} \mathrm{O}
$$

Since charged particles of the dispersed phase are present in the saponite suspension, the addition of calcium aluminum silicate inorganic coagulant is effective. The use of coagulants with strong $\mathrm{pH}$ shift to base medium will help ensure the production of large aggregates with a high deposition rate and large flakes. The destruction of the double electron layer in the saponite particle is achieved, due to the chemical activity of the inorganic coagulant.

The sample of mineral inorganic coagulant that was obtained was added to saponitecontaining water to detect the coagulating ability of the reagent. The initial content of suspended clay substances in the recycled water at the beginning of the experiment was $6320 \mathrm{mg} / \mathrm{dm}^{3}$. After $40 \mathrm{~min}$ of settling time, the spectrometric analysis showed that the turbidity of the clarified water was $278 \mathrm{mg} / \mathrm{dm}^{3}$; thus, the recycled water was purified to a level of 95\% (Figure 6).

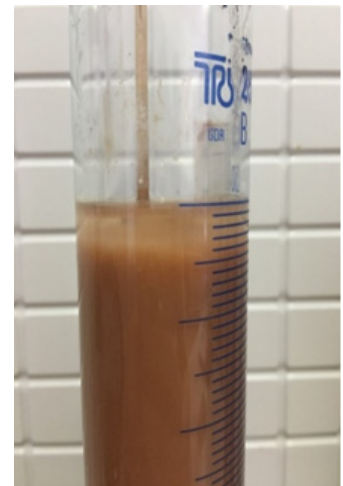

(a)

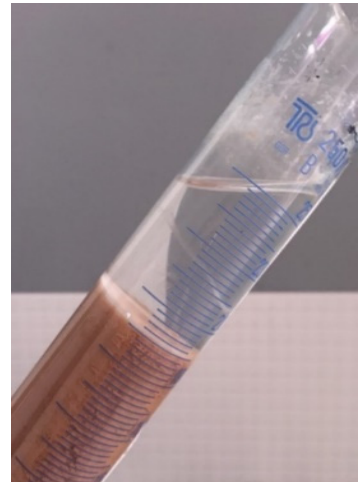

(b)

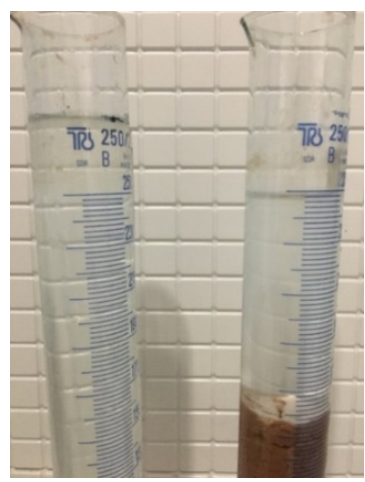

(c)

Figure 6. Verification of the coagulation properties of the obtained calcium aluminosilicate reagent sample: (a) deposition within $15 \mathrm{~min}$, (b) deposition within $30 \mathrm{~min}$, (c) comparison of pure distilled and clarified water after $45 \mathrm{~min}$ of settling time.

The study of a calcium-aluminum-silicate reagent effect on clay minerals was carried out using a TESCAN Vega electron scanning microscope with a field emission cathode at an accelerating voltage of $20 \mathrm{kV}$ in secondary electron detection mode [25]. The sample of the condensed sediment was dried at room temperature and attached to the holder with conductive carbon tape (Figure 7). 

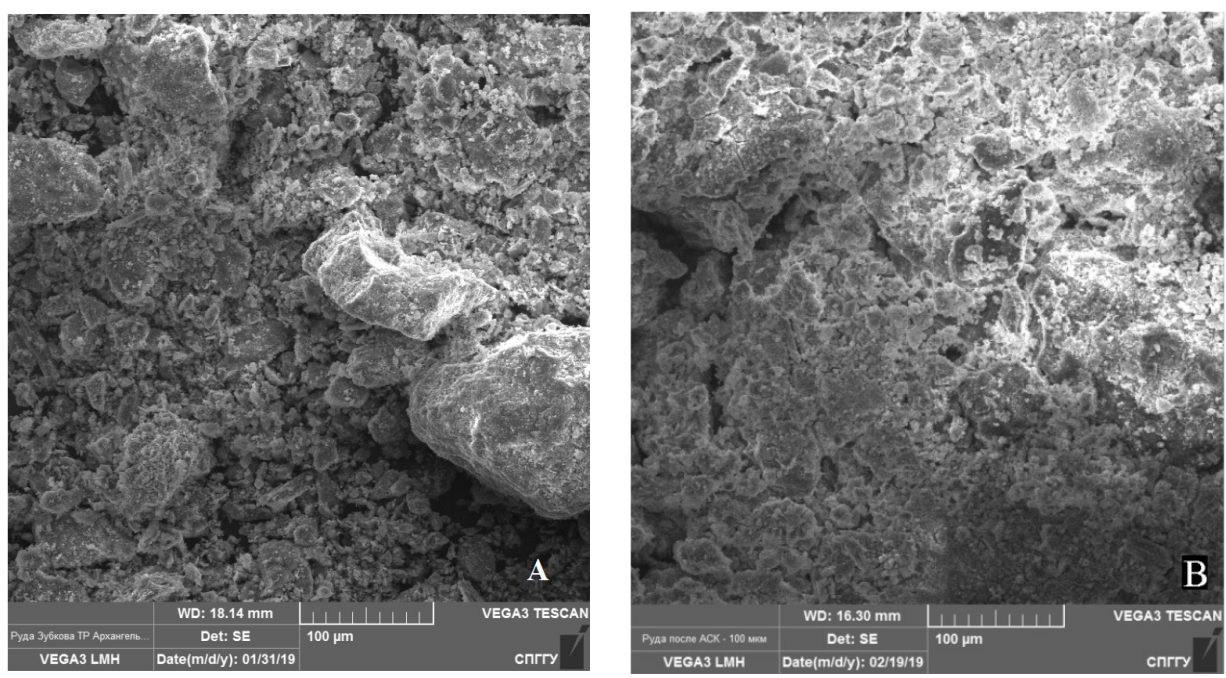

Figure 7. Pictures of the ore sample: (A) before precipitation with a calcium-aluminum-silicate reagent (field of view WD-18 mm), (B) after treatment with a reagent (field of view WD-16 mm).

The morphology of the aggregates shown in Figure 7A is specific to mixed-layer materials, which are characterized by non-pronounced morphological features. At the boundaries of large grains of angular rectilinear shapes of hydro sludges and quartz, the vague contours of montmorillonite group minerals can be seen. In Figure 7B, we can see the adhesion of separate agglomerates into a single structure after treatment with a calcium-aluminum silicate reagent.

Investigation of the optimal calcium aluminosilicate dose (Figure 8) was carried out on a sample of quarry water with $3600 \mathrm{mg} / \mathrm{dm}^{3}$ suspended particles concentration. According to the obtained results, no noticeable sedimentation occurs with a low dose of inorganic coagulant. With a $1.5 \mathrm{~g} / \mathrm{dm}^{3}$ dose of calcium aluminosilicate, sedimentation begins and has average kinetics, with an increasedof dose up to $2 \mathrm{~g} / \mathrm{dm}^{3}$ needed to reach its maximum. Trend lines areplotted to define an equation of settlement speed. An obtained trend line is sufficiently accurate for $2 \mathrm{~g} / \mathrm{dm}^{3}(99.8 \%)$, and in the case of $1.5 \mathrm{~g} / \mathrm{dm}^{3}$ dose, it has $74 \%$ accuracy. A further increase in the coagulant dose does not have any significant effect. Thus, the optimal dose is between 1.5 and $2 \mathrm{~g} / \mathrm{dm}^{3}$.

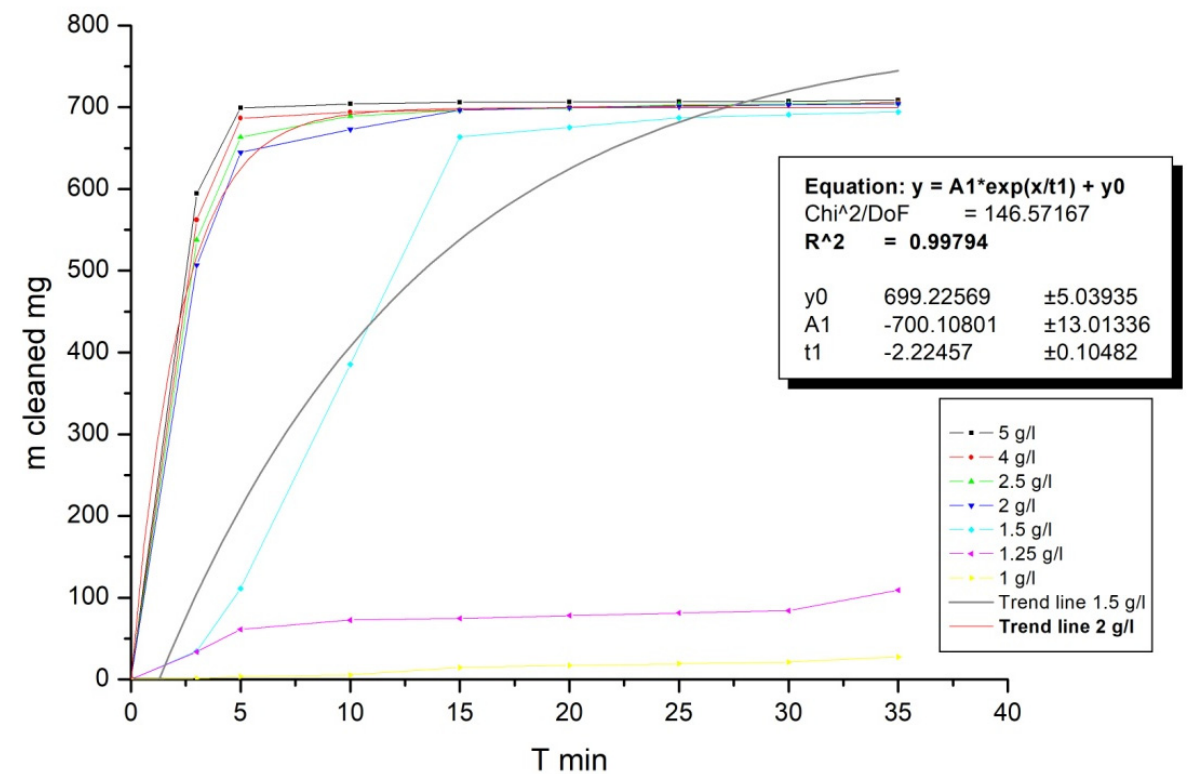

Figure 8. The concentration of suspended solids at different reagent dosages over time. 


\section{Kinetics}

The optimal calcium aluminosilicate dose (Figure 8) was investigated based on a sample of quarry water with a $3600 \mathrm{mg} / \mathrm{dm}^{3}$ concentration of suspended particles. According to the obtained results, no noticeable sedimentation occurs with a low dose of inorganic coagulant. With a $0.3 \mathrm{~g} / \mathrm{dm}^{3}$ dose of calcium, aluminosilicate sedimentation begins and has average kinetics; with an increased dose up to $0.4 \mathrm{~g} / \mathrm{dm}^{3}$, it reaches a maximum. A further increase in the coagulant dose does not demonstrate any significant effect. Thus, the optimal dose is between 0.3 and $0.4 \mathrm{~g} / \mathrm{dm}^{3}$.

Measurements of the condensed material density after $1 \mathrm{~h}$ of settling time of the saponite suspension showed that it is equal to $1.018 \mathrm{~g} / \mathrm{cm}^{3}$, which is not sufficient for dry storing. In order to increase the density of the condensed mineral, additional studies were conducted with nepheline concentrate and belite sludge as a weighting agent for condensed sediment [26-28]. According to the results of this research, it was found that the density of the condensed sediment and its cementation are much better with the belite sludge weighting agent. Belite sludge is a mixture of artificial minerals with the following composition, obtained by X-ray diffraction: belite $(\beta-\mathrm{C} 2 \mathrm{~S})(\mathrm{d}=2.89,2.74,2.41 \AA)$, calcium hydrosilicate $(\mathrm{d}=3.38,3.05 \AA)$, calcium hydrosulfoaluminate $(\mathrm{d}=2.19 \AA)$, calcium hydroxide $(\mathrm{d}=2.62 \AA)$, calcite $(\mathrm{d}=2.29 \AA)$, and unreactedalite $(\mathrm{d}=2.79 \AA)$ [29]. The main component is belite (a phase of dicalcium silicate). The $\beta$ modifications with imperfect crystallization and the $\alpha^{\prime}$ modification have high hydraulic activity [8]. The results of the condensed sludge density measurements are presented in Table 4.

Table 4. Results obtained after compaction of the thickened part.

\begin{tabular}{ccc}
\hline Seal Type & Amount of Clarified Water, $\mathbf{~ L L}$ & Density after $\mathbf{1} \mathbf{~ h , ~} \mathbf{g} / \mathbf{c m}^{\mathbf{3}}$ \\
\hline Without seal & 150 & 1.018 \\
\hline Belite sludge & 170 & 1.036 \\
\hline Nepheline concentrate & 120 & 1.029 \\
\hline
\end{tabular}

Thus, in combination with an inorganic mineral reagent, applying the belite sludge significantly increases the deposition rate of the formed particles, removes further water from the interlayer space of clay minerals, and increases the density of the condensed product [30].

The chemical composition of the condensed part permits waste-free production as shown in the $\mathrm{CaO}-\mathrm{Al}_{2} \mathrm{O}_{3}-\mathrm{SiO}_{2}$ diagram, replenishing the calcareous part of the coagulant and, thus again obtaining a reagent for the sedimentation and thickening of saponite pulp in the mining and processing plant (Table 5). The aluminosilicate obtained with calcium also has improved qualities for use in building materials and other kinds of secondary products. The production of building materials is a significant consumer of that kind of raw material and can make a significant contribution to recycling sludge from saponite waste treatment [31]. Cement composites make up the main share in the production of materials, so the involvement of secondary resources in their production is relevant $[32,33]$. 
Table 5. The chemical composition of the condensed product.

\begin{tabular}{ccc}
\hline No. & Oxide & Content, $\mathbf{w t} \%$ \\
\hline 1 & $\mathrm{SiO}_{2}$ & 28.86 \\
\hline 2 & $\mathrm{Al}_{2} \mathrm{O}_{3}$ & 6.47 \\
\hline 3 & $\mathrm{MgO}$ & 3.83 \\
\hline 4 & $\mathrm{Fe}_{2} \mathrm{O}_{3}$ & 5.8 \\
\hline 5 & $\mathrm{CaO}$ & 52.89 \\
\hline 6 & $\mathrm{~K}_{2} \mathrm{O}$ & 0.44 \\
\hline 7 & $\mathrm{TiO}_{2}$ & 0.44 \\
\hline 8 & $\mathrm{Na}_{2} \mathrm{O}$ & 0.26 \\
\hline 9 & $\mathrm{P}_{2} \mathrm{O}_{5}$ & 0.07 \\
\hline
\end{tabular}

When traditional compounds (aluminum sulfuric acid, aluminum oxychloride, polyacrylamideflocculant) are used as coagulants, it becomes almost impossible to use the condensed minerals. The hazard class of the sediment is 4 after the thickening process with aluminum sulphate, oxychloride, and polyacrylamideflocculant. After coagulation, substances in the sediment lead to certain disruptions to the ecological system, but it is able to recover in about 3 years.

\section{Conclusions}

The reprocessing of sludge is a major concern of the modern mining industry due to their environmental damage and decrease in enrichment process efficiency. In the case of diamond mining, it is especially relevant, due to the low yield of ore processing; thus, new methods of utilizing host rocks are required.

Saponite mineral is a perspective secondary product which can be applied in construction, fertilizer production, ion-exchange and other applications. Thus, a sophisticated technology of its reprocessing and utilization should be developed. Due to the particle size of the sludge, it forms a stable suspension, which tends to swell, making processing more water-intensive; settlement in natural conditions may last more than 1000 years, which makes coagulant application necessary.

Application of specially developed mineral coagulants can not only solve the problem, but it can enhance properties of saponite sludge for secondary product.

The following conclusions can be briefly drawn from the investigations performed:

1. Based on the granulometric and chemical composition of the ore and the suspension, a coagulant with specified physical and chemical properties was successfully synthesized.

2. The calcium aluminosilicate reagent is a promising coagulant for thickening clay mineral suspensions. The water was found to be purified to a level of $95 \%$.

3. Due to the astringent properties of the synthesized inorganic mineral precipitator, the load on the walls of the dam is reduced. This protects it from further damage and leads to a decrease in the areas occupied by the tailing dump.

4. The condensed sediment can be reused by restoring its calcium component. This creates the opportunity to develop waste-free diamond mining.

Author Contributions: A.A.- -development of a method for obtaining a calcium-aluminum-silicate reagent; K.K.- -development of a method for determining the deposition rate of saponite pulp using a calcium-aluminum-silicate reagent; M.R.-thermochemical calculations; O.Z.- synthesis of a calcium-aluminum-silicate reagent; interpretation of the mineral composition of the obtained reagent sample; O.K.-calculation of kinetics; A.P.-conducting an experiment on the deposition of saponite suspension with a developed coagulant and sealer. All authors have read and agreed to the published version of the manuscript. 
Funding: This research was funded by BMBF, grant No. 03Z22FN12.

Acknowledgments: The authors would like to express their gratitude to the following: V. G. Povarov an employee of the Center for Collective Use of the SPMU, for his assistance in studying the mineral composition of the ore, obtaining a laboratory sample of the reagent, and determining the granulometric composition of saponite pulp suspensions;and Shaudulina A. A., researcher at the SPMU Research Center on "Problems of processing of mineral and technogenic resources" for assistance in the study of the morphological composition of ore using the TESCANVega electron scanning microscope. Financial support for this study by the German Federal Ministry of Education and Research (BMBF, grant No. 03Z22FN12) is gratefully acknowledged.

Conflicts of Interest: The authors declare no conflict of interest.

\section{References}

1. Groshev, V.A. Ecological Situation in the Arkhangelsk Region. Abstract. 2003. Available online: https://referatbank.ru/referat/ preview /12897/referat-ekologicheskaya-obstanovka-arhangelskoy-oblasti.html (accessed on 6 October 2020).

2. Maldonado-Alameda, A.; Mañosa, J.; Giro-Paloma, J.; Formosa, J.; Chimenos, J.M. Alkali-activated binders using bottom ash from waste-to-energy plants and aluminium recycling waste. Appl. Sci. 2021, 11, 3840. [CrossRef]

3. Sofi, M.; Sabri, Y.; Zhou, Z.; Mendis, P. Transforming municipal solid waste into construction materials. Sustainability 2019, 11, 2661. [CrossRef]

4. Rollo, H.A.; Jamieson, H.E. Interaction of diamond mine waste and surface water in the Canadian Arctic. Appl. Geochem. 2006, 21, 1522-1538. [CrossRef]

5. Pavlova, K.I.; Fedchenko, A.A.; Iseeva, L.I. Comparative analysis of production and economic activities of Russian and foreign diamond mining enterprises. J. Min. Inst. 2012, 196, 189.

6. Händel, F.; Fichtner, T.; Graeber, P.-W. Numerical and Laboratory Investigations of Closely-Spaced and Joint Infiltration of Precipitation and Treated Waste Water. Water 2019, 11, 2262. [CrossRef]

7. Official Website of PJSC Severalmaz. Available online: http://www.severalmaz.ru/investoram/godovye-otchety/ (accessed on 13 May 2018).

8. Zubkova, O.S. Complex Processing of Saponite Ores with the Addition of Alkaline Aluminosilicate Raw Materials: Thesis; Olga Sergeevna Zubkova.-Special Publication: Saint-Petersburg, Russia, 2020; p. 131.

9. Vaganov, V.I.; Golubev, Y.K.; Minorin, V.E. The "Diamonds" issue. In Methodical Guidelines for Estimating the Forecast Resources of Diamonds, Precious and Non-Ferrous Metals; Golubev, Y.K., Ed.; TsNIGRI: Moscow, Russia, 2002; p. 106.

10. Oblitsov, A.Y.; Rogalyov, V.A. Prospective Directions of Utilization of Waste from the Enrichment of the Diamondiferous Rock of the Deposit Named after M.V. Lomonosov. J. Min. Inst. 2012, 195, 163-167.

11. Alekseev, A.I. Calcium Hydro Aluminates and Hydro Garnets (Synthesis, Properties, Applications); LSU Publish: Leningrad, Russia, $1985 ;$ p. 184.

12. Utin, A.V. Method of Thickening the Saponite. Suspension. Patent No. 2448052, 20 April 2012.

13. PashkevichMariya, A.; Alekseenko, A.V. Reutilization prospects of diamond clay tailings at the Lomonosov mine. Northwestern Russ. Miner. 2020, 10, 517.

14. Tutygin, A.S.; Aizenshtadt, M.A.; Aizenshtadt, A.M.; Makhova, T.A. Influence of the nature of the electrolyte on the coagulation process of a saponite-containing suspension. Geoecology 2012, 5, 470-474.

15. Sizyakov, V.M.; Brichkin, V.N. On the role of calcium hydrocarboaluminates in improving the technology of complex processing of nepheline. J. Min. Inst. 2018, 231, 292.

16. Sizyakov, V.M.; Sizyakova, E.V.; Kononenko, E.S. Crystallization of calcium hydrocarboaluminates in the $\mathrm{CaCO}_{3}-\mathrm{Na}_{2} \mathrm{O}-\mathrm{Al}_{2} \mathrm{O}_{3}-$ $\mathrm{H}_{2} \mathrm{O}$ system. J. Min. Inst. 2012, 197, 230.

17. Bakharev, S.A. Purification of Circulating Water of a Diamond Mining Enterprise on the Alluvium Map by an Acoustic Method. ObogashchenieRud 2014, 6, 3-6.

18. Davy, A.T.; Smith, C.B.; Helmstaedt, H.H.; Jaques, A.L.; Gurney, J.J. Geoscience and Exploration of the Argyle, Bunder, Diavik, and Murowa Diamond Deposits; Number 20; Society of Economic Geologists, INC. Special Publication: Littleton, CO, USA, 2018; pp. 1-13.

19. Zhang, C.; He, H.; Petit, S.; Baron, F.; Tao, Q.; Gregoire, B.; Zhu, J.; Yang, Y.; Ji, S.; Li, S. The Evolution of Saponite: An Experimental Study Based on Crystal Chemistry and Crystal Growth. Am. Mineral. 2021, 106, 909-921. [CrossRef]

20. Feklichev, V.G. Diagnostic Spectra of Minerals; Nedra: Moscow, Russia, 1989; p. 479.

21. Wilson, D.; Amos, R.T.; Blowes, D.W.; Langman, J.B.; Smith, L.; Sego, D.C. Diavik Waste Rock Project: A Mechanistic Approach To The Prediction Of The Geochemical Evolution Of Sulfidic Waste Rock. In Proceedings of the 11th ICARD IMWA MWD Conference-Risk to Opportunity/Proceedings IMWA2018 Annual Conference, Pretoria, South Africa, 10-14 September 2018; pp. 406-410.

22. Alekseev, A.I.; Alekseev, A.A. Water chemistry: Textbook, handbook. In Two Books. Book II; KHIMIZDAT: St. Petersburg, Russia, 2007; p. 456. 
23. Makarova, I.A. Physico-Chemical Methods of Research of Building Materials: Textbook/I.A.; Lochova-BryatskBrSU: Makarova, NA, USA, 2011; p. 139.

24. Naber, C.; Bellmann, F.; Sowoidnich, T.; Goetz-Neunhoeffer, F.; Neubauer, J. Alite Dissolution and C-S-H precipitation Rates during Hydration. Cem. Concr. Res. 2018, 115, 283-293. [CrossRef]

25. Nazarenko, M.Y. Influence of Temperature on the Total Surface Area of Nanopores of Leningrad Deposits Oil Shale. Key Eng. Mater. 2020, 854, 194-199. [CrossRef]

26. Karapetyan, K.; Dzhevaga, N. Technology of processing of apatites in the production of fused phosphates as modern highly effective fertilizers. In Proceedings of the 17th International Multidisciplinary Scientific GeoConference SGEM 2017, Albena, Bulgaria, 29 June-5 July 2017; Volume 17, pp. 939-946.

27. Kononchuk, O.O.; Goncharova, M.V.; Hippmann, S.; Bertau, M.; Alexeev, A.I. Recovery of $\mathrm{CaCO}_{3}$ from the Nepheline Sludge of Alumina Production / Rückgewinnung von $\mathrm{CaCO}_{3}$ ausdemNephelinschlammderAluminiumoxidproduktion. Chem. Ing. Tech. 2019, 91, 494-501. [CrossRef]

28. Shaidulina, A.A.; Kondrasheva, N.K.; Shaidulina, A.A.; Kondrashev, D.O.; Georgieva, E.Y.; Vasil'ev, V.V. The nepheline concentrate in synthesis of NaX-type zeolites. In Innovation-Based Development of the Mineral Resources Sector: Challenges and Prospects, 11th Conference of the Russian-German Raw Materials, Potsdam, Russia, 11 October 2019; CRC: Boca Raton, FL, USA, 2019 ; pp. 407-412.

29. Andreeva, N.A. Chemistry of Cement and Binders: Textbook/N. A. Andreeva; SPbSABU: St. Petersburg, Russia, $2011 ;$ p. 46.

30. Sizyakov, V.M.; Brichkin, V.N.; Kurtenkov, R.V. Increasing all-round utilization of nepheline raw materials through belite sludge soda conversion. Obogashchenie Rud 2016, 1, 54-59. [CrossRef]

31. Gu, X.; Tan, H.; He, X.; Smirnova, O.; Zhang, J.; Luo, Z. Utilization of Carbide Slag by Wet Grinding as an Accelerator in Calcium Sulfoaluminate Cement. Materials 2020, 13, 4526. [CrossRef] [PubMed]

32. Kazanskaya, L.F.; Smirnova, O.M.; Palomo, Á.; Menendez Pidal, I.; Romana, M. Supersulfated Cement Applied to Produce Lightweight Concrete. Materials 2021, 14, 403. [CrossRef] [PubMed]

33. Smirnova, O.; Kazanskaya, L.; Koplík, J.; Tan, H.; Gu, X. Concrete Based on Clinker-Free Cement: Selecting the Functional Unit for Environmental Assessment. Sustainability 2021, 13, 135. [CrossRef] 